\title{
O TEMPO COMO SUBSTANCIALIDADE DO TRABALHO: 0 TEMPO INDUSTRIAL E O TEMPO DE TRABALHO.
}

\section{TIME AS WORK SUBSTANTIALITY: INDUSTRIAL TIME AND WORK TIME.}

Cássio Adriano Braz de Aquino ${ }^{1}$

\section{Resumo}

O propósito desse artigo é discutir a importância da articulação das categorias tempo e trabalho, partindo da idéia de que as transformações do mundo do trabalho podem ser pensadas como transformações na estrutura temporal do trabalho. Tendo como referencial teórico as teorias dos tempos sociais e a concepção de tempo dominante, analisamos a perfeita aliança entre o tempo industrial e o ordenamento social, que coloca o trabalho como a atividade social central da organização da temporalidade social da modernidade. O tempo permanece como substancialidade do trabalho e constitui um elemento privilegiado de estudo do mundo laboral

Palavras-Chave: Trabalho-tempo-industrialização

\begin{abstract}
The intention of this article is to discuss the relevance of the joint between time and work categories, starting with the idea that the transformations on the work world can be thought as transformations on the temporal structure of work. With the theories of the social times and the conception of dominant time as theoretical referential, we analyze the perfect alliance between the industrial time and the social order that places the work as the central social activity on the organization of the social temporality of modernity. Time remains as work substantiality and constitutes a privileged element of study on the labor world.
\end{abstract}

Key words: Work, time and industrialization

\section{Introdução}

O presente trabalho é derivado de uma reflexão empreendida durante a realização do Doutorado em Psicologia Social na Universidade Complutense de Madrid e tem por objetivo dar prosseguimento a uma série de articulações entre a 
categoria tempo e a categoria trabalho dentro do contexto de transformações do mundo laboral.

O nosso referente básico é a compreensão da temporalidade como elemento de análise da realidade do trabalho e o impacto dessa vinculação para o desenvolvimento de novas matrizes para a discussão do mundo laboral no território da Psicologia Social do Trabalho.

Segundo as teorias dos tempos sociais, através da idéia de alguns dos seus grandes expoentes - Roger Sue, Gilles Pronovost, George Gurvitch, Ramon Ramos entre outros -, a estrutura social estaria delineada pela dominância de uma determinada atividade social. $O$ tempo associado a essa atividade seria 0 tempo referente para ordem social. Foi assim com o tempo sagrado das primeiras civilizações, com o tempo religioso que vigorou fundamentalmente na Idade Média e seria esse o caso do tempo de trabalho, no seio da Sociedade Industrial.

No texto que hora desenvolvemos centraremos nossa análise na emergência desse tempo dominante associado à atividade do trabalho e na constituição do paradigma do tempo industrial como tempo dominante da modernidade.

\section{O tempo como substancialidade do trabalho}

Grimaldi (2000) ao enfocar a ontologia do trabalho, admite que tal como se percebe hoje, o estatuto do trabalho está profundamente influenciado por dois fatos históricos decisivos: a condição salarial e o mercantilismo. Essa constatação conduz a uma excessiva generalização, que leva a reconhecer como trabalho qualquer atividade de caráter obrigatório ou mesmo qualquer atividade remunerada. Para esse autor, tal constatação é o que conduz a 'monstruosidades morais e conceituais', havendo necessidade de liberar a categoria trabalho das tentações da linguagem que deram origem a uma multiplicidade de atividades tão heterogêneas na sua caracterização.

Ao tentar dar conta da ontologia do trabalho, Grimaldi (2000) toma o tempo como um mediador para delimitação da categoria trabalho. Partindo do 
pensamento de Hegel - que concebia o trabalho como o "negativo a industriosa obstinação do que, no presente, conspira sem cessar aniquilá-lo e criar o que não existe ainda" (Hegel apud Grimaldi, 2000; p.23) - ele vê no trabalho uma certa militância do futuro no presente. Está claro que ao conceber a capacidade criadora e antecipada, envolvida no próprio sentido do trabalho, o autor está reconhecendo seu caráter mediador. $O$ trabalho exerce uma ação direta sobre a temporalidade na sua tentativa de antecipar no presente a configuração do futuro. Em suas próprias palavras:

O trabalho não expressaria outra coisa que a obstinação do futuro que tende, sem cessar, amanhecer no presente. Independente de toda forma que tome, não seria todo trabalho em realidade nada mais que o trabalho do tempo?De forma mais determinante ainda: uma expressão assim não seria uma redundância? Pois, haveria tempo se não houvesse devir, e poderia alguma vez advir algo se nenhum trabalho preparasse seu surgimento? $O$ trabalho não seria nada mais que o dinamismo, 0 exercício ou a operação mesmo da temporalidade? Mas se fôssemos levados a não conceber o trabalho sem o tempo, não nos perguntaríamos se o trabalho é só um transcendental do tempo? (Grimaldi, 2000; p. 22)

Está claro que a referência de Grimaldi não se restringe a concepção de trabalho caracterizada pela sociedade salarial. É a concepção ampliada da categoria que serve de referência para o autor. $O$ trabalho da negatividade é o que vai permitir a constituição do devir, enfrentando a aparente inércia das coisas que tende a manter-se no presente. Esta negatividade está caracterizada, pois, por um esforço de transformação e esse esforço faz da temporalidade uma ação laboriosa. Aprofundando mais sua reflexão, Grimaldi (2000) introduz a noção de prazo, considerada como constitutiva da consciência que temos do tempo e como a evidência que estamos voltados ao futuro. É a consciência ontológica do prazo, como ressalta o autor, o que nos mantêm vinculados à tendência do 'por-vir', tendência que pode ser vivida e compreendida como a própria resistência do presente em sua oposição ao futuro.

Seria prudente voltar nosso olhar ao pensamento de Luhmann (1976/1992) sobre a articulação social do passado, presente e futuro. É importante recordar que Luhmann considera que ocorreu na sociedade moderna uma exacerbação de temporalização da realidade, diretamente associada às profundas 
transformações da semântica temporal. A idéia de um futuro aberto e tomado como uma tendência, nunca como uma realização concreta, gera estratégias de normalização do devir, seja através do domínio técnico, seja através da utopia.

A idéia da resistência do presente pode ser difícil de admitir, uma vez que a tendência cronológica da temporalidade nos leva a imaginar o tempo como uma representação linear que articula passado, presente e futuro em uma linha contígua. Se assim fosse, porém, nos bastaria apenas esperar para que as coisas se transformassem. Grimaldi (2000) não crê na capacidade do tempo transcorrer por sua própria inércia. Ele crê, sobretudo, que o trabalho do tempo não cessa nunca e afirma ainda que, quando imaginamos que nada ocorre, o tempo já começou a 'minar nossa espera' e 'debilitar nossa atenção'. Se assim não fosse, nos levaria a compreender que haveria tempo sem mudança, da mesma forma que não haveria necessidade de mudança operada no tempo. Para Grimaldi (2000), pois, o trabalho opera a transformação e a transformação é o tempo. Tempo e trabalho se articulam em uma circularidade atravessada pela noção de tendência. A tendência é compreendida como um constante trabalho do futuro no presente. Não há como separar o tempo do trabalho, eles compõe uma sólida aliança, explicada por Grimaldi da seguinte forma: (...) posto que não haveria tempo sem prazo, nem prazo sem resistência, nem resistência sem esforço, nem esforço sem tendência, o trabalho seria então uma só coisa com o tempo" (Grimaldi, 2000; p.24).

A identidade ontológica entre tempo e trabalho é uma boa ilustração da complexa articulação entre as duas categorias. No entanto, a adoção da estratégia de articulação entre passado, presente e futuro, parece distanciar-se das evidências mais concretas de corte mais topológico e cronológico (num sentido quase 'cronométrico') que parecem associar empiricamente a temporalidade e o trabalho dentro de um contexto específico da modernidade. Há um momento claro de caracterização do tempo como elemento central tanto para os indivíduos como para o sistema econômico. Há um fenômeno privilegiado onde a vinculação entre tempo e trabalho adquire traços de perfeita harmonia, o que de alguma forma provoca uma idéia de visibilidade ou evidência concreta mais além de uma 
possível identidade ontológica. Essa articulação, sem dúvida, está na base das reflexões que desembocarão no surgimento de um campo de estudo sobre o tempo social. Além disso, com base nesse conjunto de conhecimentos se faz viável uma melhor compreensão de como se estrutura a ordem social. Esse momento tem como ícone a Revolução Industrial, mas é o processo de industrialização em sua evolução ou transformação o que servirá de território para nossa reflexão. Nos deteremos aqui numa discussão de como se constituiu essa relação harmônica entre industrialização e tempo.

\section{O tempo industrial e o tempo de trabalho}

Pronovost (1996) ressalta que a descrição da gênesis histórica da Revolução Industrial Inglesa, que faz Thompson (Thompson apud Pronovost,1996), é uma das melhores sínteses da ruptura de um tempo social e o conseqüente surgimento de uma nova temporalidade. Segunda sua aportação, nas sociedades mais tradicionais e de corte mais agrícola, a medida do tempo estava orientada pela tarefa. O tempo tinha um caráter muito mais qualitativo, orientado pelas atividades, mas a industrialização rompe com essa idéia. A introdução do 'industrialismo' operou uma mudança que levou a que tarefas executadas durante o trabalho passassem a ser controladas pelo tempo. Ademais, de forma determinante, a opção pelo tempo como medida de valor, o vincula diretamente a questão do dinheiro. O tempo se torna assim, uma moeda.

A transformação operada na vinculação 'tempo x trabalho' aponta para uma alteração de sentido em ambas as categorias. Se por um lado o tempo passa a ser visto como uma grandeza que deve ser controlada com rigidez, o trabalho também muda de perspectiva, já que o controle do tempo dedicado ao trabalho sai do ritmo natural que havia marcado as sociedades tradicionais e passa a ser submetido a um tempo mecânico, controlado pelo relógio.

O estabelecimento da indústria rompe com a relação próxima entre o tempo de trabalho e a vida mesma. Um dado claro que acentua essa transformação pode ser pensado também com relação a espacialidade laboral. Gasparini (1996) 
destaca que nas sociedades pré-industriais não havia uma especialização entre o espaço de trabalho e o espaço privado. Estava claro que tomando por referência os agricultores, havia uma contigüidade espacial entre o campo que cultivavam e sua habitação rural. Para o artesão não havia distinção entre o seu atelier e sua casa. Dessa forma a indiferenciação espacial, ou seja, a contigüidade do território implica uma referência pouco relevante de distinção entre os tempos sociais que compunham as sociedades pré-industriais, uma vez que a proximidade permitia a alternância de ações de trabalho e de vida sem profundas rupturas.

É importante ressaltar que a separação espacial que se dá de forma acentuada com o estabelecimento da Sociedade Industrial, constitui um marco fundamental da especialização dos tempos sociais. O fenômeno da concepção sob o mesmo 'teto' - que se dá com o surgimento das fábricas - e a sincronização temporal - que marca a produção, são considerados elementos fundamentais para a atribuição de uma organização temporal que vai ser denominada de 'tempo industrial'.

É curioso fazer referência ao critério da espacialidade, pois hoje, a reestruturação espacial do trabalho, caracterizada pela desconcentração e dessincronização produtiva configura um dos elementos mais significativos da profunda transformação da temporalidade laboral na contemporaneidade.

O grupo que compõe Ėchanget Projets (1980) ressalta que a história do tempo é a história do seu crescente domínio e a era industrial é o exemplo mais evidente do surgimento de uma 'racionalidade temporal' fruto da intensificação das transformações da organização produtiva e das redes comerciais.

Toda a história da industrialização será uma luta de patrões por controlar o tempo dos seus empregados, inclusive o tempo fora do trabalho. Ocorra o que ocorra, é necessário induzir os trabalhadores a reservar todas as suas energias à produção e, por isso, incutir neles os valores produtivistas: assiduidade, pontualidade e manutenção do esforço.(Tradução livre, Ėchange et Projets, 1980; p.67).

É possível constatar que a Revolução Industrial é também uma revolução da concepção do tempo, um tempo que adquire relevo e destaque por vincular-se diretamente ao trabalho. Com ela surge um sistema produtivo distinto e um novo 
meio social de produção: a fábrica. Com ela surge também uma alteração profunda no tempo social dos atores individuais, ou seja, os trabalhadores.

Marx já destacava no Capital, no livro V (1976), a importância do tempo de trabalho como núcleo do sistema capitalista, por sua concepção de fator de determinação da remuneração dos trabalhadores. Ademais, destacaria sua importância como elemento fundamental da produção moderna, ao reconhecer como primeira lei básica da produção social, a economia de tempo e da distribuição programada dos tempos de trabalho nos distintos ramos da produção.

Recorrendo ao pensamento de Attali (1985), é interessante reconhecer que o símbolo da industrialização é o relógio. Nesse contexto o ciclo que marca a organização e o transcurso do tempo é a produção. O tempo de exceção seguindo a idéia de Attali sobre a alternância temporal que caracteriza a ordem social nas sociedades pré-industriais - já não é o tempo das feiras e carnavais, mas o das pausas diárias, necessárias para recomposição da força do trabalhador. Com a industrialização se passa a priorizar o tempo das máquinas, sendo seu mais concreto representante o relógio. A busca da precisão e a idéia da sincronização fazem desse objeto à própria metáfora da vida social.

Com o uso dos relógios, os homens podem empregar todos os momentos necessários nos trabalhos (...) da vida civil. O homem organiza, mediante eles, a hora do trabalho e a do repouso, a da sua comida e do seu sono. E, por essa afortunada distribuição do tempo, a sociedade mesma caminha como um relógio, e forma, quando está bem organizada, uma espécie de engrenagem cujos movimentos sucessivos são os trabalhos de todos os membros que a constituem.(radução Livre; Berthoud in Atalli, 1985; p. 155).

É possível ir mais além na compreensão do relógio como metáfora da ordem social que surge com a industrialização. São os relojoeiros os grandes responsáveis pela criação das máquinas que vão dar novo impulso à produção e alterar a idéia de sistema produtivo. As criações industriais são quase sempre dedutíveis das invenções destinadas a relojoaria. Ademais, já no século XVII, de forma precoce, e, mais efetivamente no século XVIII, o próprio modo de produção do relógio como objeto industrial, é um exemplo de divisão do trabalho e 
especialização produtiva. Uma citação de Petty (1680) no livro de Attali (1985) já destacava a característica precursora da fabricação do relógio:

\begin{abstract}
Em uma cidade extensa, as indústrias se vincularão uma a outra e cada uma das indústrias estará dividida em tantas partes como seja possível, para que seja simples e fácil o trabalho do artesão. Por exemplo, na fabricação de um relógio, se um homem fabrica os ponteiros, outro as molas, se outro mais o fundo e se ainda outro fabrica a carcaça, o relógio será melhor e menos custoso que se um só homem se encarregar de todo o trabalho. (Petty in Attali, 1985; p.161).
\end{abstract}

Com a industrialização, pois, o controle da produção é também o controle do tempo. A origem do tempo industrial estava assim ancorada em três aspectos fundamentais destacados por Pronovost (1996): a regularização do trabalho, a divisão do trabalho e a disciplina do tempo de trabalho.

Com relação ao primeiro aspecto é importante ressaltar o fato de que no principio da era industrial, em função da débil planificação da demanda, o trabalho era realizado de forma muito irregular. As jornadas laborais costumavam ser bastante variadas e podiam mudar em função das condições climáticas ou mesmo por ausência de demanda, entre outras coisas. Não se percebe nos primeiros momentos da industrialização, uma alteração radical com relação à concepção temporal que havia prevalecido nas sociedades tradicionais. Progressivamente se introduz a noção de sincronização e é fundamentalmente com o modo de produção taylorista-fordista que esta encontra seu ápice. No entanto, é importante reconhecer que essa irregularidade, típica dos primórdios da industrialização capitalista, gerava a idéia de dedicação intensiva ao trabalho, pois a ausência de garantias e o risco permanente de perder a remuneração do trabalho provocavam tal atitude. Esse dado nos parece muito relevante por que não é muito distinto do fenômeno que caracteriza parte dos vínculos laborais atuais, observados é lógico um outro contexto sócio-histórico e cultural.

A divisão do trabalho estava marcada pela diferenciação e especialização crescente e ao segmentar o processo produtivo, a produção industrial substitui de forma decisiva a figura do artesão. Tal divisão, segmentando o processo produtivo, abre a possibilidade de que cada etapa tenha sua própria 
medida de tempo. A disciplina do tempo de trabalho remete a idéia de uma estruturação do tempo baseada na atividade laboral. $O$ trabalho, que passa a ter um tempo controlado, determina o tempo de outras atividades. Em princípio essa determinação se insere quase que absolutamente sob a dualidade 'tempo de trabalho x tempo de não-trabalho'.

Essa dualidade está também na base do pensamento de um dos mais importantes teóricos da sociologia do trabalho, George Friedmann. Friedmann (1961) pode ser apontado também como um dos precursores da sociologia do ócio/lazer - também da comunicação e da educação -, e é em torno do trabalho e seu mais evidente 'opositor', o ócio, que ele desenvolve uma das mais destacadas contribuições à renovação e impulso da sociologia dos tempos sociais.

Friedmann (1961) destacava a importância do trabalho com relação ao âmbito da temporalidade na sociedade moderna, ressaltando dois aspectos centrais. O primeiro é a concepção do trabalho como portador de um tempo específico e ao mesmo tempo tomado como elemento técnico, possível de ser organizado e racionalizado. O segundo aspecto por ele destacado, é que o tempo de trabalho na era da industrialização tem um caráter ambivalente, já que estava ao mesmo tempo na essência do sistema técnico e como produto do funcionamento das técnicas de produção e do maquinário.

A exemplo de outros autores, Friedmann reconhece uma ruptura instalada a partir da introdução de uma 'racionalidade' do tempo industrial. Para ele, a industrialização e de forma destacada a empresa capitalista, subverte a relação entre o tempo e o trabalho, pois conduz o tempo a configurar-se como medida do trabalho, quando antes, o trabalho e as demais atividades sociais de uma maneira geral, constituíam a medida do tempo. Essa ruptura ou subversão é responsável pela transformação do trabalho em um conjunto de gestos funcionais e impessoais.

A idéia da centralidade do tempo como atributo de valor apontado por Marx, é apoiada por Friedmann, que passa a reconhecer no trabalho antes mesmo que uma ação sobre a natureza, uma vivência de sua própria temporalidade. 0 trabalho é o 'tempo de trabalho', marcado, sobretudo, pela idéia da venda da força 
de trabalho por parte dos trabalhadores. Como humanista, ele critica a imposição do tempo mecânico que foi adotado pela rotina da industrialização e que conduziu ao menosprezo do tempo de criação e inovação.

Se não há uma referência direta de Friedmann (1961) à questão dos tempos sociais, não se pode negar que seu intento de discutir a relação entre os distintos tempos das atividades sociais com relação ao tempo mecânico do trabalho industrial, constitui uma das mais significativas contribuições ao estudo dos tempos sociais.

Sue (1995) ao analisar a importância da industrialização na estruturação da nova ordem social recorre ao seu modelo teórico sobre o tempo dominante. Ele aponta que no princípio da industrialização começa a surgir uma contradição entre o domínio do tempo religioso e a configuração de um tempo que ele denomina de mercantil. A referência de que 'todo o tempo pertence a Deus', como afirmava Le Goff (1971), rivalizava com uma constatação cada vez mais evidente de autonomização do tempo de trabalho. O predomínio do tempo religioso não perdura muito. Ainda com a tentativa de negociação entre a Igreja e - Capital, visando adaptar e adequar o tempo de trabalho e as premissas religiosas, o tempo religioso sucumbe frente ao tempo de produção e da indústria.

A ilustração do processo de transformação do domínio temporal pode ser reforçada com a alusão a outros eventos significativos tais como o crescente movimento de urbanização, a especialização do trabalho e o impulso do comércio interior e exterior. Tudo isso deixava claro que já não era mais possível compaginar tempo religioso e tempo da indústria.

O tempo se torna quantitativo, cada vez mais homogêneo no sentido onde, desde o ponto de vista da mercadoria um dia é igual à outro dia. Totalmente oposto ao tempo qualitativo da Igreja, onde um dia é identificado a um santo específico. O ciclo da mercadoria supõe um tempo relativamente contínuo que não está de acordo com as descontinuidades e rupturas do calendário religioso. Ademais, o comércio com outros países necessita uma unidade de medida comum, o que reforça ainda mais a forma quantitativa do tempo. A conquista do espaço passa pela conquista do tempo despossuído dos seus atributos místicos, reduzidos a uma forma numérica que se imponha por sua racionalidad. (Tradução livre, Sue, 1995; p158). 
É impossível compreender essa mudança sem fazer referência a obra de Weber (1981). Ele afirma que o ethos do trabalho advém com a nova concepção do tempo. A reforma protestante e a perda de poder da Igreja Católica são fenômenos evidentes e fundamentais dessa transformação. O protestantismo introduz a idéia de que aceder aos caminhos de Deus é realizar uma obra e o trabalho é o mais digno desses caminhos.

Sue (1995) afirmava que passar da 'profissão de fé', de caráter eminentemente espiritual, a uma profissão vinculada ao logro material, era uma metáfora perfeita da transição do tempo religioso ao tempo industrial.

Como também destaca Attali (1985), a evidência simbólica de diminuição do condicionamento do tempo religioso está representada pela substituição dos sinos pelos relógios. A colocação dos relógios nos antigos campanários das Igrejas é uma alusão clara do surgimento de um novo espírito do tempo e de sua nova representação

A idéia que passa a prevalecer - nesse deslocamento do tempo tradicional/religioso, imposto exteriormente, para um tempo moderno, onde os valores e as normas são personalizados - é que ocorre uma individualização do tempo. Dessa observação surge a noção de que o próprio indivíduo passa a ser o responsável pela utilização do seu tempo. A industrialização passa a ser caracterizada por uma extensão de horas trabalhadas em espaços quase sempre fechados, sob um forte controle do tempo. Muitas vezes esse controle estava determinado por um critério de resistência física. A secularização do tempo conduz a uma substituição das igrejas pelas empresas e a conseqüente adoção da lógica quantitativa e de coação, fazendo com que o apito da indústria impusesse o ritmo social.

Produtora do tempo, a empresa está no centro da vida social, como estava a Igreja [nas sociedades tradicionais]. Os ritmos da cidade estão sob seu controle. Melhor, as cidades em sua totalidade se constituem e se desenvolvem a partir de uma empresa (...) E se pode, portanto, comparar as empresas e as catedrais. Catedrais dos tempos modernos.(Tradução livre, Sue, 1995; p. 167). 
Está claro, pelo que foi descrito anteriormente, que a industrialização introduziu uma nova concepção de temporalidade, mas é importante observar que, se a atividade laboral desenvolvida no espaço das empresas era ao mesmo tempo o grande modelo de organização do tempo e o referente por excelência da noção de trabalho, ela não era a única. Essa observação nos parece pertinente por que revela que para além desse modelo - metáfora de toda uma forma de estruturação social - existiam sociedades que mantinham as formas de estruturação mais tradicionais. Além disso, é importante frisar que a industrialização não foi um modelo generalizado em todos os territórios do globo. Não podemos nos esquecer ainda a advertência de Elias (1997) sobre a tendência a uma referência quase sempre ocidental e capitalista da análise das transformações sociais.

Países com um processo de industrialização tardio, como os latinoamericanos, começaram a configurar-se sob essa composição temporal somente em meados do século $X X$, por exemplo, quando já se iniciava a reestruturação produtiva em alguns países. Mais que a industrialização é o trabalho, em uma concepção mais ampla de categoria, que conduz a idéia defendida pelos teóricos dos tempos sociais do domínio da temporalidade.

Essa breve reflexão histórica nos serve de subsídios para pensar a complexidade da categoria tempo e da categoria trabalho, longe de um referencial determinístico e hegemônico que vigorou na modernidade e que começa a desafiar uma nova forma de conceber não só a articulação de tais categorias, mas a própria estruturação social da contemporaneidade, mas isso é tema para outro debate.

\section{Referências Bibliográficas}

AQUINO, C. (2003) 'Tiempo y trabajo: un análisis de la temporalidad laboral en el sector de ocio - hostelería y turismo - y sus efectos en la composición de los cuadros temporales de los trabajadores'. Tesis Doctoral presentada en el departamento de Psicología Social de la Universidad Complutense de Madrid.

ATTALI, J. 1985) Historias del tiempo. México: Fondo de Cultura Económica. 
Échange et Projets (1980) La révolution du temps choisir. Paris: Albin Michel.

ELIAS, N. Sobre el tiempo. México: Fondo de Cultura Económica, 1997.

FRIEDMANN, G. (1961) A donde va el trabajo humano? Buenos Aires: Sudamericana.

GASPARINI, G. (1994) La dimensione sociale del tiempo. Milano: Angeli.

.(1996) 'Tempo e trabalho no ocidente' in Chanlat, J-F (1996) O indivíduo nas organizações: dimensões esquecidas (vol III). São Paulo. Atlas, pp. 111-126.

GRIMALDI, N. (2000) El trabajo: comunión e excomunicación. Navarra: Ediciones Universidad de Navarra.

LE GOFF, J. (1971) La baja edad media. México: Siglo XXI.

LUHMANN, N. El futuro no puede empezar: estructuras temporales en la sociedad moderna. En: RAMOS TORRE, R. Tiempo y sociedad. Madrid: Centro de Investigaciones Sociológicas, 1992, p. 161-182.

PRONOVOST, G. (1996) Sociologie du temps.Bruxelles: De Boeck.

RAMOS, R. (1992) Tiempo y sociedad. Madrid: Centro de Investigaciones Sociológicas.

SUE, R. (1995) Temps et ordre social. Paris: PUF. 
1 Professor do Departamento de Psicologia da UFC. Doutor em Psicologia Social pela Universidad Complutense de Madrid. Email: braz.aquino@uol.com.br

Nota dos Editores: Artigo recebido 01/05/2008. Aprovado em 21/05/2008. 